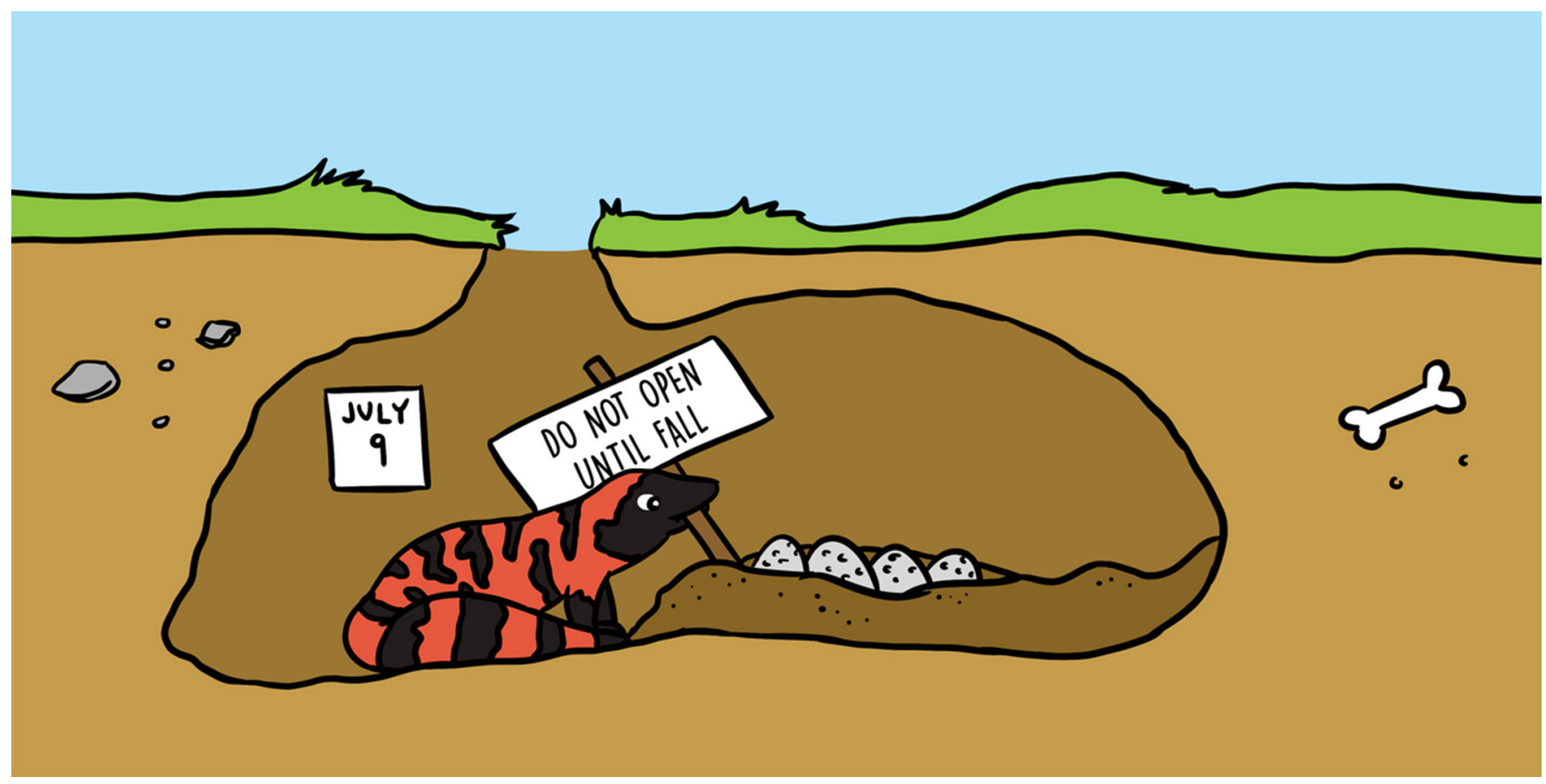

\title{
THE GILA MONSTER EGG PUZZLE
}

Karla T. Moeller ${ }^{1 *}$ and Dale F. DeNardo²

${ }^{1}$ Office of the University Provost, Arizona State University, Tempe, AZ, United States

${ }^{2}$ School of Life Sciences, Arizona State University, Tempe, AZ, United States

\section{YOUNG REVIEWERS:}

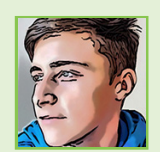

GREG

AGE: 15

KATI

AGE: 15
Young animals must fight for survival. Animals that hatch underground have better chances of surviving if they emerge when conditions outside are good. But what if the end of development does not line up to when conditions outside are good? The time between when an egg is laid and when the hatchling emerges can sometimes be changed. Changing this time may help hatchlings avoid predators and find water and food. Hatching can be delayed through a process called diapause, when development stops for a period of time. A less common strategy is for hatchlings to wait in the nest after hatching. In vertebrates, waiting in the nest over winter and emerging in spring had only been observed in some turtle species. But we have now found that Gila monsters also use this strategy. Turtles and Gila monsters are very different, which helps us explore factors that might cause this strategy to evolve. 


\section{BURROW}

A natural hole or tunnel that an animal lives or hides in.

\section{EMERGE}

To come out or appear

\section{DIAPAUSE}

A period when development stops temporarily.

\section{HATCHLING}

An animal that recently hatched from an egg

\section{AN EGGY MYSTERY}

A Gila monster pokes her head into a hole, flicks her tongue to "smell" her surroundings, and enters the burrow. Inside, she wanders between tunnels, looking for a place to lay her eggs. When she finds a good place, she will typically lay four to six eggs. Soon after, she will leave the nest, and her job as mother to those eggs will be over. In the wild, Gila monsters lay eggs in July. Their young do not emerge from the burrow until over 9 months later, between May and August the following year. But when Gila monsters lay eggs in captivity, the eggs hatch after about 4 months [1]. Why is this timing so different in captivity versus in the wild? There are two main possibilities.

In captivity, egg temperature is kept fairly constant. But in the wild, temperatures change with the seasons as the egg develops over several months. These changes may cause eggs to go into diapause (a process in which development stops for a while) during the winter until it warms up and development starts again. Another possibility is that wild Gila monster eggs hatch in autumn, but because autumn is chilly and there is not much food around, the hatchlings may wait for nearly 5 months before they emerge. If this were the case, they would spend winter in the nest.

\section{WHO OVERWINTERS IN THE NEST?}

In places where the temperature changes across seasons, winter is the coldest part of the year. During winter, many animals greatly reduce their activity, often finding burrows or other retreats to stay in until spring. However, these retreats are not usually the same retreats in which they were born or hatched.

One exception is turtles. Some adult turtles wait out the cold of winter under water in ponds or lakes that may freeze over. Overwintering under water can be a problem for young turtles, because it is hard for them to deal with the very low levels of oxygen (water is $<1 \%$ oxygen, while air is $21 \%$ oxygen). So, if overwintering underwater would not work, where can hatchlings safely spend the winter? In burrows, underground. But, there is one more problem. Turtle embryos are not very resistant to freezing. If it gets too cold, embryos still within eggs could die, while hatchlings have a better chance of surviving. For the best chance of survival, some baby turtles hatch from their eggs (so they would not freeze) and wait in their nests (to get enough oxygen) until spring, when the weather warms and they emerge [2]. 


\section{OVERWINTER}

To live through winter.

\section{GRAVID}

Pregnant.

\section{Figure 1}

Nest pitfall traps. Metal flashing was used to surround all nest entrances (which are also exits), and pitfall holes were dug, with buckets placed inside, along the inner edge of the flashing. When hatchling Gila monsters left the nest, they would head out and walk along the flashing until they fell into a pitfall trap.

Gila monsters are very different from aquatic turtles, but our team thought Gila monster hatchlings might also overwinter in the burrows where they hatched. To find if this was true, we pieced together three main clues.

\section{PIECING TOGETHER THE GILA MONSTER PUZZLE}

Young Gila monsters are a rare thing to see. We increase our odds of observing them if we trap hatchlings as they emerge. We followed gravid (pregnant) Gila monsters to the nests where they laid their eggs. Later in the year, we set up "pitfall" traps around the nests, to catch what came out. We set up a wall of thin metal ("flashing") around a burrow. Then, we dug pits (holes) that animals fell into as they tried to leave the burrow. The traps were designed to safely hold hatchling Gila monsters until we found them. Using this method (Figures 1, 2), we observed when hatchlings left two burrows. We found that in the wild, hatchlings from the same nest can start emerging in early May, with some leaving as late as early August.

Once we knew when Gila monsters were likely to emerge, we tested whether temperatures in the wild caused eggs to go through a diapause. To record the temperature of a wild nest, we first surgically placed a temperature recorder and a radio transmitter (to track location) inside the body of several female Gila monsters. Some of those females later started to develop eggs. Then, when a female was ready to lay eggs, we used this equipment to find her and her nest site. The temperature recorder is an iButton; it is the size of a stack of five dimes and is coated in plastic, so it does not harm the animal. It recorded her temperature every hour. When she went into the burrow to lay eggs, she stayed there for around 10 days. When she left, we set up a system that measured

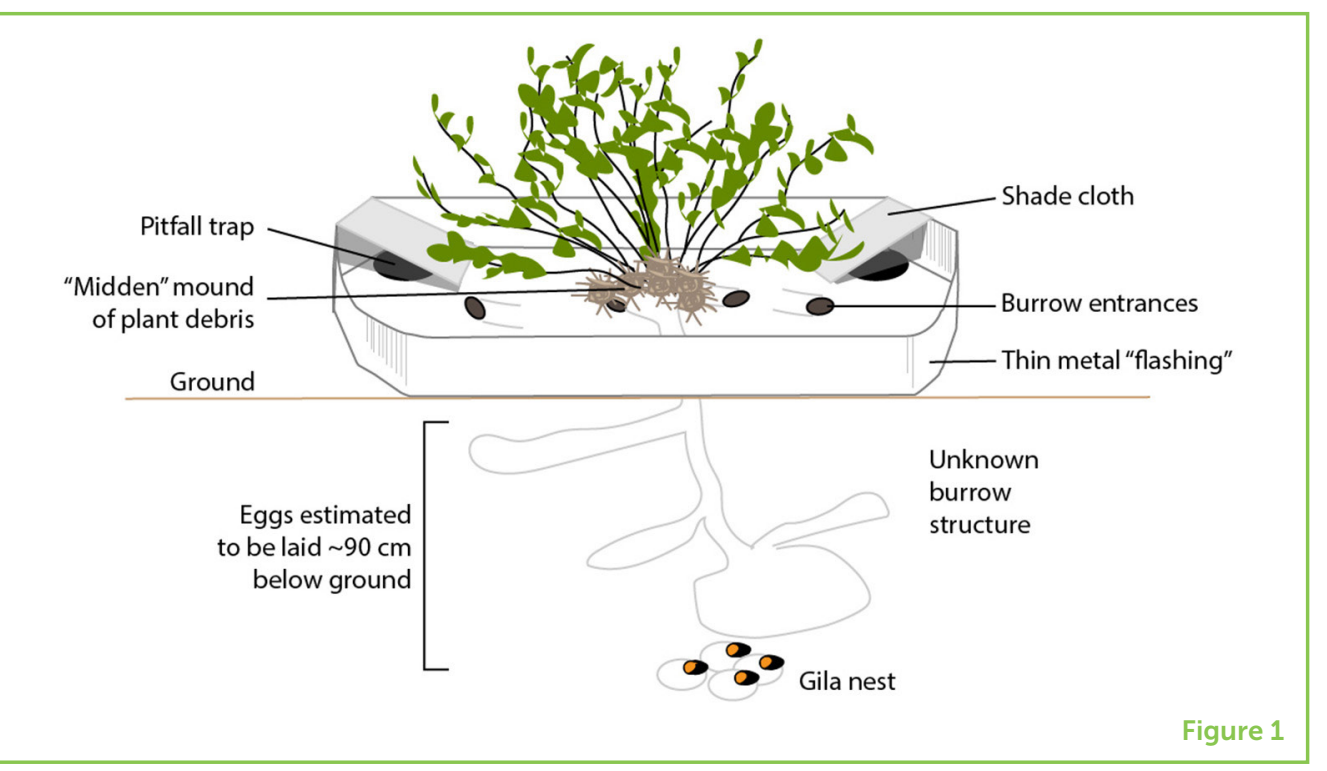


Figure 2

A hatchling Gila monster that has fallen into a pitfall trap.

Figure 3

Temperatures used to incubate Gila monster eggs in the lab. The purple line shows a fairly constant temperature, often used to develop Gila monster eggs in captivity. The orange dotted line shows the temperature profile recorded from a nest in the wild, and you can see that the temperature is variable over time.

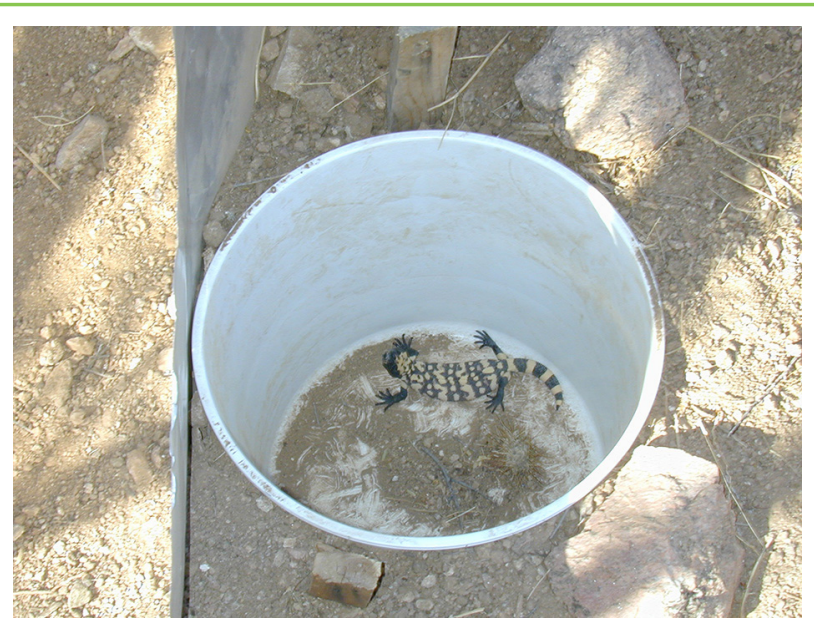

Figure 2

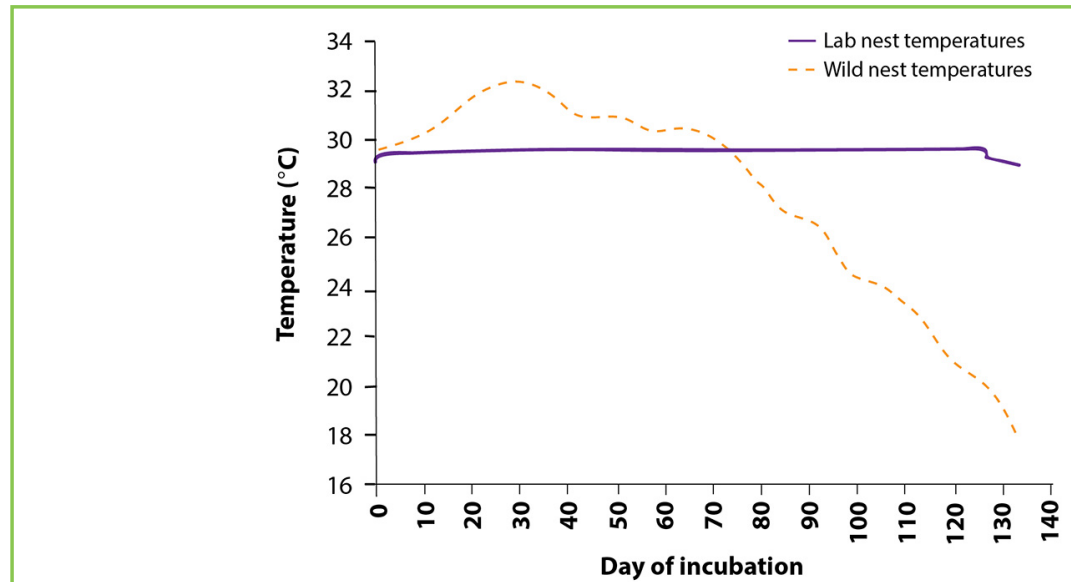

Figure 3

soil temperature in the burrow. We recorded temperature at several depths $(15,30,60$, and $90 \mathrm{~cm})$ for a year, from July when she laid her eggs, until the following July, after several hatchlings emerged.

We compared the female Gila monster's body temperature when she was in the burrow to the temperature of the soil right after she left. Based on the temperatures, we estimated that she laid her eggs 90 $\mathrm{cm}$ below ground. Using the temperature data for that depth, we then controlled the temperature of developing Gila monster eggs in the lab (Figure 3). Eggs that developed at wild nest temperatures did not go through a diapause. Those eggs hatched in 4 months, matching an autumn hatching for wild eggs. This, when combined with the pitfall trap data indicating that hatchlings leave the burrow in late spring and summer, was very strong evidence that wild Gila monsters hatch in autumn and overwinter in their nests or burrows.

The last bit of evidence came to our team by accident. A home was being remodeled near Tucson, Arizona, and the construction team dug 
up a Gila monster nest. It was October, and some eggs in the nest had hatched. Other eggs were in the process of hatching. Clearly, these eggs had not gone through a diapause. Instead, the Gila monsters were likely going to wait in the nest or burrow for around 5 months and emerge in spring or summer.

\section{WHY HATCH INSTEAD OF WAITING IN THE EGG?}

If a hatchling is going to wait to emerge and it is not at risk of freezing in the egg (it rarely freezes in the Sonoran Desert), diapause would seem to be a good strategy. Diapause would save energy in the young Gila monsters, giving them better chances of survival... but this is where venom may come into play. If a Gila monster is stuck in an egg, and another animal wants to eat the egg, there is not much the Gila monster can do. It might end up as a predator's lunch. However, Gila monsterseven hatchlings - have sharp teeth and a painful, venomous bite. They have a pretty good chance of defending themselves, as long as they are not stuck inside an egg. This defense may be one of the benefits leading to the evolution of overwintering in the nest.

\section{WHY WAIT TO EMERGE?}

Now we know why hatching early, as opposed to undergoing diapause, might be beneficial... but why wait to emerge? If you have hatched, why not emerge right away or at least as soon as temperatures are warm enough? Gila monsters only eat animals from other vertebrate nests. Where Gila monsters live, no vertebrates reproduce in late autumn. After winter, most adult Gila monsters start to become active in March, when temperatures warm. At this time, small birds and small mammals (like rabbits and rats) start breeding and making nests that hold eggs or young-food for adult Gila monsters. But Gila monster hatchlings are too small to eat these things. Instead, they mainly eat the tiny eggs of small lizards. Those small eggs are not available until late spring or early summer, when the hatchling Gila monsters emerge. If the hatchlings left the nest and looked for food as soon as temperatures warmed, they would likely just waste energy without finding food, because there would not be any lizard eggs out there.

Instead, the young Gila monsters most likely spend their time in the nest, living off of two energy sources. First, when they hatch, they have small stores of yolk in their bellies, and they likely drink any fluid or egg white left in their own eggs. They can live off of this unused energy for weeks. Gilas are also born with fat stored in their tails. They rely on this fat to get them through the winter. Winter is cold, which lowers their 
body temperatures. With low body temperature comes low energy use, so hatchlings can survive until spring without eating, especially if they do not waste energy searching for non-existent food.

\section{CONCLUSION}

Development and hatching of wild animals can be hard to study, especially when these processes occur below ground. But these studies help explain the timing of certain behaviors, like emergence. Our evidence shows that at least some Gila monsters hatch in the fall and overwinter in the nest until spring or summer. Nest overwintering helps the hatchlings stay warm, defend themselves, and emerge when food is available. Overall, these data show that nest overwintering is not just for turtles. There may be other vertebrates that overwinter in the nest as hatchlings, but we need more studies to figure that out. As we learn about other species that do this, we can better understand factors that can lead to evolution of nest overwintering.

\section{AUTHOR CONTRIBUTIONS}

Both authors helped design the study, collect the data, and analyze the data. For this submission, KM drafted the manuscript and both authors edited the manuscript.

\section{ORIGINAL SOURCE ARTICLE}

DeNardo, D. F., Moeller, K. T., Seward, M., and Repp, R. 2018. Evidence for atypical nest overwintering by hatchling lizards, Heloderma suspectum. Proc. R. Soc. B Biol. Sci. 285:20180632. doi: 10.1098/rspb.2018.0632

\section{REFERENCES}

1. Beck, D. D. 2005. The Biology of Gila Monsters and Beaded Lizards. Berkeley, CA: University of California Press.

2. Costanzo, J. P., Lee Jr., R. E., and Ultsch, G. R. 2008. Physiological ecology of overwintering in hatchling turtles. J. Exp. Zool. A Ecol. Genet. Physiol. 309A:297-379. doi: 10.1002/jez.460

SUBMITTED: 10 August 2018; ACCEPTED: 24 January 2019; PUBLISHED ONLINE: 27 February 2019.

EDITED BY: Vishal Shah, West Chester University, United States 

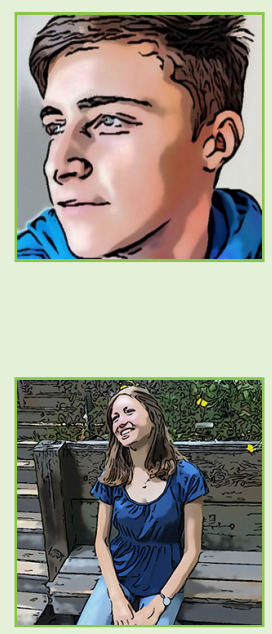

\section{KATI, AGE: 15}

I am a Sophomore in high school who enjoys reading and playing the double bass. I love science and am especially interested in animal behavior. I am excited to participate in Frontiers for Young Minds because it enables me to learn new things outside of school as well as share new discoveries with my peers.

\section{AUTHORS}

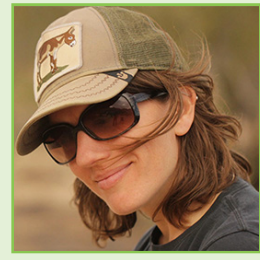

\section{KARLA T. MOELLER}

I work in education, outreach, and research at Arizona State University, where I manage the program Ask A Biologist. I do research on education and on animal ecology. My animal research focuses on how animals survive in extreme environments, and how survival strategies and behaviors change throughout life. I also love to spend time hiking and writing. I am a children's book author, and write books with messages about growing up and supporting community and diversity. *karla.moeller@asu.edu

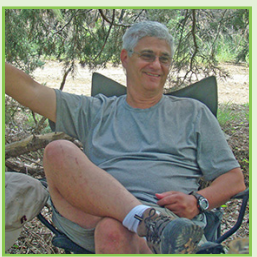

\section{DALE F. DENARDO}

I am a Veterinarian and Professor at Arizona State University, where I oversee the care of animals on campus and conduct research exploring how animals survive in challenging environments. I am especially interested in animals that live in deserts where, for much of the year, it can be quite hot with a very limited availability of food and water. Despite these conditions, I love to spend time in the desert observing and learning about the animals that I study and love. 